\title{
Exploring How Research Experiences For Teachers Changes Their Understandings Of The Nature Of Science And Scientific Inquiry
}

\author{
Sanlyn R. Buxner, University of Arizona \& Planetary Science Institute, USA
}

\begin{abstract}
The nature of science is a prevalent theme across United States national science education standards and frameworks as well as other documents that guide formal and informal science education reform. To support teachers in engaging their students in authentic scientific practices and reformed teaching strategies, research experiences for teachers offered in national laboratories, university research centers, and national field-sites promise opportunities to help teachers update their current understanding of STEM fields and experience firsthand how scientific research is conducted with the end goal of supporting more inquiry-based teaching approaches in their classrooms. This qualitative interpretive study used an adapted Views of Nature of Science and Views on Scientific Inquiry surveys and protocols to investigate changes in 43 practicing teachers' understandings about the nature of science and scientific inquiry as a result of participation in one of three summer science research programs. Each program provided participants with research experiences alongside professional researchers as well as activities intended to increase participants' abilities to provide inquiry-based science learning activities for their students. Data were collected using open-ended surveys pre-program, post-program and long-term follow-up surveys, semi-structured interviews, focus groups, along with researcher's observations and field-notes. Participation in these programs led to small, measurable enhancements in teachers' understandings of scientific inquiry and the nature of science. Teachers' prior experience with research was found to have the strongest relationship to their knowledge of the nature of science and scientific inquiry. The data in this study provides evidence that research experiences can provide valuable experiences to support teachers' improved knowledge of how science is conducted.
\end{abstract}

Keywords: Teacher Education; Nature Of Science; Scientific Inquiry; Research Experience For Teachers; K-12 Professional Development

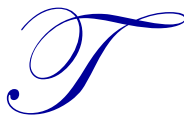

he Next Generation Science Standards (NGSS) (Achieve, 2013) outline recommendations for how to effectively engage K-12 students in science by integrating disciplinary core science ideas, crosscutting concepts, and science and engineering practices. Additionally, these standards describe eight understandings of the nature of science (NOS) including: 1) Scientific Investigations Use a Variety of Methods, 2) Scientific Knowledge is Based on Empirical Evidence, 3) Scientific Knowledge is Open to Revision in Light of New Evidence, 4) Scientific Models, Laws, Mechanisms and Theories Explain Natural Phenomena 5) Science is a Way of Knowing, 6) Scientific Knowledge Assumes an Order and Consistency in Natural Systems, 7) Science is a Human Endeavor, and 8) Science Addresses Questions About the Natural and Material World. These ideas are largely consistent with previous national standards and frameworks documents emphasizing that students should be active participants in actively doing science and in the process of learning science (viz., AAAS, 2009; Luera \& Otto, 2005; NRC, 1996, 2000, 2011). Education researchers have suggested that teachers' firsthand science research experiences may be a prerequisite for adopting inquiry-oriented teaching of scientific practices (Adamson 
et al., 2003; Dresner \& Worley, 2006; Windschitl, 2003). However, data to support these assertions resulting from systematic research across multiple programs using similar protocols is highly limited. The recommendations of these authors, among others, and the National Science Education Standards (NSES) (NRC, 1996, 2011), assert better science teaching results when teachers have had authentic research experiences as a part of teacher education. In response to recommendations that teachers would be better supported in helping their students learn authentic scientific practices, scientific research opportunities for teachers have expanded greatly in the last decade. These research programs now exist throughout the United States and are run by universities, national laboratories, and private organizations. The programs occur in experimental laboratories and at field sites where teachers participate in research activities along with professional researchers (NSF, 2014; Tobias \& Baffert, 2009). Experiences are usually held over the summer when teachers have fewer classroom teaching responsibilities. These program vary in length from one to ten weeks and often provide participants with a financial stipend. Some programs feature additional academic year components and provide specific classroom-ready curriculum with supporting pedagogical workshops.

The overall goal of these programs is to provide teachers with experiences doing research alongside scientists in an authentic setting. The often explicit assumption of these programs is that by providing teachers with this authentic science experience they will become better science teachers which may lead to improved student performance in science (O’Neal, 2003; Silverstein, Dubner, Miller, Glied, \& Loike, 2009). This intention to improve teachers' efficacy in the classroom is addressed in different ways by different programs but usually relates to at least one of the following: increase in science content knowledge, increase in understanding of how science is actually conducted, increase in interest in science, being able to talk knowledgeably about science and science careers, an increase in using research in the classroom, and increase in using reformed learner-centered teaching methods. Although many of the experiences of science research programs may include lectures, teachers are generally expected to learn by participating in scientific practices and actively construct their own knowledge during their research experiences. Many research programs for teachers are also based on apprenticeship models in which working alongside a master leads to the transmission of practices and knowledge from experts to novices (Lave \& Wenger, 1991). Often the tacit assumption is that as teachers do some of the day to day work of scientists, teachers will transform this knowledge into better classroom teaching.

There is a general consensus among scholars and educators that understanding the nature of science is a critical piece of science literacy (viz., AAAS, 1993; Deng, Chen, Tsai, \& Chai, 2011; Driver, Leach, Millar, \& Scott, 1996; Lederman, 2007; Schwartz, Lederman, \& Crawford, 2004), and that this should be shared among both teachers and students. Lederman (2007) proposed in his well-regarded review of nature of science studies in education that general principles of science knowledge are tentative, empirical, and include subjective aspects of science as well as the influence of human inference, creativity and imagination, and society and culture. Despite some critique of these elements for use in K-12 classrooms by Elby and Hammer (2001), this led to work by Lederman, Abd-El-Khalick, Bell, and Schwartz (2002) on creating an open-ended assessment instrument and protocol to explore students' and teachers' understandings of nature of science is the basis for many current studies of nature of science. This VNOS instrument and protocol is widely used by science education researchers.

Schwartz and Lederman (2006), in their description of their progress toward finalizing open-ended instrument to assess understandings of scientific inquiry, defined aspects of scientific inquiry to include: knowledge about multiple methods of investigation ("myth of a single scientific method"), understandings about how scientific investigations are related to current knowledge and research agendas, the role of argumentation in development and acceptance of new knowledge, understanding of anomalous data, the distinctions between data and evidence, and the role of peer review and communication in that scientific knowledge is negotiated in a social setting. They argued that a distinction between nature of science (NOS) and scientific inquiry (SI) helps in understanding the difference between the product of inquiry, scientific knowledge (NOS), and the processes of inquiry and how knowledge is generated and accepted (SI).

Currently, the Views of Nature of Science instrument is one of the most widely used instruments to assess nature of science understandings. As described by the authors, Lederman, Abd-El-Khalick, Bell, and Schwartz (2002), the VNOS is an open-ended survey that was designed to probe participants' understandings about the following aspects of NOS: the tentative nature of scientific knowledge, the empirical nature of science, the theory- 
laden aspects of science, that science is partially a product of human inference, imagination and creativity, the differences between observations and inferences, the lack of a universal method for doing science, and the relationship between scientific theories and laws (p. 499). An additional, related, instrument developed to target student and teachers' understandings about scientific inquiry is the Views of Scientific Inquiry (VOSI) (Schwartz, Lederman, \& Thompson, 2001; Schwartz, 2004; Schwartz \& Lederman, 2008, Schwartz, Lederman, \& Lederman, 2008). As described by the authors, the VOSI was designed to probe the follow aspects of scientific inquiry: questions drive investigations, multiple methods of scientific investigations, multiple purposes of scientific investigations, the form and role of argumentation in the development and acceptance of new knowledge, recognition and handling of anomalous data, sources, roles of, and distinctions between data and evidence (Schwartz \& Lederman, 2008). The VNOS is meant to focus on the epistemological foundations of scientific knowledge whereas the VOSI is meant to focus on scientific processes. Although distinct, the two instruments incorporate some overlapping ideas. Thus it is possible to use both instruments together to investigate conceptions of both nature of science and scientific inquiry. The distinction that Lederman (2007) makes between nature of science and scientific inquiry is not as stringently adhered to in studies where other researchers used the VNOS and VOSI (viz., GessNewsome, 2002).

Although many studies have published results using the VNOS alone, almost all studies that use the VOSI often also included the VNOS (Akerson, Townsend, Donnelly, Hanson, Tira \& White, 2009; Gess-Newsome, 2002; Schwartz \& Lederman, 2008; Schwartz \& Lederman, 2004, Schwartz, 2004). As described by these authors, the VOSI can be used as a complement to the VNOS for understanding participants' understandings of science. These studies, and others, show that using the VNOS and VOSI are effective tools for assessing teachers' understandings of nature of science and scientific inquiry. Unlike many multiple choice or Likert-scale instruments, the VNOS and VOSI allow researchers to collect information about participants' ideas in their own words and provide more information than simply a quantitative score. This combination is judged to be ideal for studying how teachers learn science through research.

This paper describes and documents part of a larger study that was designed to investigate the potential impact that participating in a science research program had on 1) science teachers' understandings of scientific inquiry and the nature of science 2) their beliefs about science teaching, and 3) their reported classroom practice that led them to engage students in science practices aligned with the NGSS. Results related to changes in teachers' understanding of the nature of science and scientific inquiry as a product of research experiences are presented here, whereas results describing impacts on classrooms are reported elsewhere (Buxner, 2010).

To better understand how authentic research experiences for teachers impact teachers' understanding of the nature of science and the nature of inquiry, the following questions guided this study:

1. How do teachers' conceptions of the nature of science and scientific inquiry change as a result of participating in a research experience for teachers?

2. How are teacher research experiences connected to changes in teachers' understanding of scientific inquiry and nature of science?

\section{METHOD}

This study utilized qualitative inquiry methods to collect participants' own words about their understandings and perception to make sense of changes in attitudes, beliefs and understandings. The study design is a multiple-groups, multiple-measures, qualitative approach. This data provided holistic views, and not numeric values, of participants' understandings and beliefs.

\section{Participants}

Forty-three participants from three summer research experiences for teachers facilitated by three different organizations during the summer of 2008 volunteered to participate. These three programs occurred at a large state research university, at a national lab, and a program funded by NASA. These programs were selected for this study 
because of their long-standing reputation for providing high quality professional development for teachers and for having programs that were widely-advertised and highly-subscribed.

\section{GROUP ONE: Chaco Educator Institute In Astronomy}

The Chaco Educator Institute in Astronomy (Chaco) was a NASA funded one-week field-based program in Chaco Culture National Historic Park in Chaco Canyon, New Mexico. It featured both hands-on field experience and classroom activities and tangible resources to help improve teachers' astronomy, earth science, and cultural astronomy instruction. Participants worked alongside research scientists both in the field, during the classroom discussions and lab work. Throughout the week, 15 participants engaged in astronomy activities geared toward $\mathrm{K}$ 12 classrooms presented by professional astronomy educators, participated in short research experiences related to archaeoastronomy, and completed a several day research experience in Chaco investigating archeological sites with a research mentor.

\section{GROUP TWO: Arizona Science Teacher Advancement and Research Training Program}

The Arizona Science Teacher Advancement and Research Training Program (AZ-START), was an ongoing program run by the University of Arizona in collaboration with Arizona's universities, community colleges, and other public and private research enterprises. Funded by Science Foundation Arizona, 17 teachers were selected to participate in the Tucson-based program. Due to the location of their mentors and research sites, not all teachers were present in Tucson at any one time. Most teachers attended a one-week training session at the University of Arizona at the beginning of the summer to prepare them for their research experience. Teachers then conducted lab or field research in various locations throughout the state of Arizona with a research mentor or mentor team for up to eight weeks. Throughout the summer teachers participated in various activities including colloquia and professional research lunch presentations at the University of Arizona in Tucson.

\section{GROUP THREE: Astronomy Research Based Science Education}

The Astronomy Research Based Science Education (A-RBSE) workshop, formerly Teacher Leaders in Research Based Science Education (TL-RBSE), was a program run by the National Optical Astronomy Observatory (NOAO). It was originally funded by a grant from the National Science Foundation (NSF) and had been an ongoing yearly program for teachers for the past ten years. The program was open to high school teachers who had been teaching science for at least five years, were interested in doing authentic astronomical research with their students, and committed to doing astronomical research with their classes for at least two years after their participation in the program. Seventeen teachers participated in the Tucson and Kitt Peak ten-day workshop and research experience. In the year of this study, the program included a one-semester online course that covered astronomical imaging, spectroscopy and topics related to future work that was to be done in residence before the ten-day workshop in Tucson, AZ which included four nights of observation with research-grade telescopes alongside professional astronomers, and gave teachers future opportunities to bring students to do astronomical research at the National Observatory on Kitt Peak.

\section{Procedures}

Data were collected through an open-ended written survey that was administered pre- and post- program as a holistic measure of participants' understandings of scientific inquiry (SI) and nature of science (NOS). It was a shortened version compiled from the Views of Nature of Science (VNOS) form C (Lederman, Abd-El-Khalick, Bell, \& Schwartz, 2002), and the Views of Scientific Inquiry (VOSI-Sci) (Schwartz, Lederman, \& Lederman, 2008). On the modified survey combined from VNOS and VOSI-Sci, there is no one-to-one nature of science/scientific inquiry aspect to questions. Instead, multiple questions on the instruments were used to assess participants' understandings of target aspects of scientific inquiry and nature of science. Additionally, data were collected during the programs from the researcher's field-notes, individual and focus group interviews with teacher participants during the programs, and artifact analysis. During the interviews and focus groups, teacher participants were asked about why they chose to participate in the program, their philosophy of science teaching, their views of scientific inquiry related to their responses on the survey, and about aspects of their research program. Six participants, two from each 
program, were interviewed six to nine months after the end of each research program. These follow-up phone interviews probed teachers' reflections on their research experience and asked about specific answers they had given on the pre- and post- surveys.

\section{Data Analysis}

Initial descriptive codes were developed by reading participants' survey responses using standard qualitative-inquiry methods advocated by Miles and Huberman (1994). This initial code sheet was revised by both reading participants' responses and by drawing on existing studies with published analyses of participants' views of the nature of science and views of scientific inquiry (Lederman, Abd-El-Khalick, Bell, \& Schwartz, 2002; Schwartz, 2004). The targeted NOS/SI aspects included the myth of the scientific method, multiple ways to conduct scientific investigations, multiple purposes of scientific inquiry, the empirical nature and justification of science, the empirical absolute versus tentative nature of science, the roles of anomalous data, the sociocultural nature of science, and the use of creativity in science. The pre- and post- surveys resulted in 84 descriptive codes which were collapsed into 33 interpretive categories and compared to categories described in the literature cited earlier. Each was then binned into four broad categories based on the overall category of response: (i) descriptive, (ii) learning, (iii) informed, and (iv) naïve.

Analysis for possible change in beliefs was conducted only for participants who completed both a pre- and post- survey, a total of 38 sets, across the three research programs: 12 participants in the Chaco program, nine participants in the AZ-START program, and 17 participants in the A-RBSE program. Once the code sheet was finalized, each pre- and post- survey was re-coded according to the target NOS/SI categories. Each survey was coded independently by the author and another highly-qualified science education researcher. For inter-rater reliability, the judged categorizations were compared for consistency. The few discrepancies occurred because the responses were sometimes judged as descriptive because it was vague which were easily resolved to consensus. Changes to participants' answers from pre- to post- were documented and a profile was developed for each participant including their pre, post, and any changes detected in understandings relating to scientific inquiry and nature of science. In addition to analysis of the written responses, when an interview was completed with a participant, transcripts were analyzed using the same codes developed for the written responses. The interview transcripts were compared to participants' written responses to confirm or alter participants' profiles. All of the information was used to designate an overall categorization of each participant's views of the targeted aspects of scientific inquiry and nature of science.

Below are examples of participants' naïve and informed responses to each of the NOS/SI target aspects. Participants were classified as holding a mixture of views of a target NOS/SI aspect if their responses contained both naïve and informed ideas.

\section{Myth Of The Scientific Method}

The target aspect "myth of the scientific method" refers to the fact that there is no one "scientific method" that all scientists follow to conduct investigations and that there is no strict algorithmic way to do science. Responses that were coded as naïve for this target aspect included responses that involved a rigid set of steps or the idea that there was one algorithmic way to conduct scientific investigations. Below is an example of a response coded as naïve for this target aspect.

Science is testing hypothesis using strict rules. It differs from other disciplines in that it often demands a rigid set of steps in coming to conclusions. (Ch-7)

Responses coded as informed for this target aspect included talking about multiple ways to conduct scientific investigations, that questions often drive scientific questions, and that there was no algorithmic way to do all science. Below is an example of a response coded as informed for this target aspect.

Science is the quest for knowledge...it is the logical way to organize evidence and our experiences into a framework or hierarchy of information... Good scientific knowledge stems from asking testable questions 
and making relevant observations and or testing workable hypotheses. It is difficult to do "experiments" in some areas such as Astronomy but one can develop questions and hypotheses. (RB-5)

\section{Multiple Ways To Conduct Scientific Investigations}

The target aspect "multiple ways to conduct scientific investigations" refers to the idea that there are many ways beyond controlled two-group comparison experiments to collect evidence and conduct valid scientific investigations including observations and modeling. Responses that were coded as naïve for this target aspect included talking about controlled experiments as the sole way to gather scientific data. Below is an example of a response coded as naïve for this target aspect.

Yes. I think scientific knowledge requires experiments because you need to support a hypothesis which is based on something physical. Also, you must have experiments so you can grow and iterate the experiment so that you are testing what you really want to test. (AZ-8)

Responses coded as informed for this target aspect included a discussion of other ways to gather data including modeling and observations. Below is an example of a response coded as informed for this target aspect.

Scientific knowledge does not always require experiments - careful observation is also key. Two examples - a study of bird migration, where bird locations are carefully mapped, or an observational study of quasars. Both are valid scientific studies even though they don't involve variables, control groups etc. $(R B-10)$

\section{Multiple Purposes Of Scientific Inquiry}

The target aspect "multiple purposes of scientific inquiry" refers to the idea that scientists choose to pursue scientific investigations from multiple kinds of questions that serve multiple purposes including their own curiosity, solving problems, and helping society. Responses were coded as naïve for the target aspect "multiple purposes of scientific inquiry" if they included ideas about all science being driven by a single purpose. Below is an example of a response coded as naïve for this target aspect.

All science has the same the same purpose - to test hypotheses. (AZ-12)

Responses that were coded as informed for this target aspect included a discussion of multiples purposes of scientific investigations driven by questions, problems and curiosity. Below is an example of a response coded as informed.

One purpose of scientific inquiry is to gain understanding. Generally a more specific reason for scientific inquiry is to solve a problem. (RB-15)

\section{Empirical Nature And Justification Of Science}

The target aspect "empirical nature and justification of science" refers to how science is based on evidence and how science is justified. Responses were coded as naïve for the target aspect if they included ideas about science leading to one answer, only one way to interpret evidence, and the perceived objective nature of science. Below is an example of a response that was coded as naïve for this target aspect.

Science is more objective than other disciplines and leads us to one right answer. (Ch-7)

Responses were coded as informed for this target aspect if they discussed how science is based on previous work, the use of logic and systematic investigations that support scientific claims, the predictive nature of science models, the reproducible aspects and how evidence may be interpreted in multiple ways. Below is an example of a response coded as informed for this target aspect. 
A question arises for which no answer exists. A process by which the question can be answered is determined. The process is carried out, often with unforeseen elements. The data that are gathered are analyzed and the limits of the process are also identified. Facts are then published with indications of these limits, along with the process, in a manner that enables other to reproduce the findings. (RB-2)

\section{Empirical Absolute Versus Tentative Nature Of Science}

The target aspect "empirical absolute versus tentative nature of science" refers to the idea that science is not absolute, that it cannot prove facts or find truths but that it is about supporting ideas, and is open to change with new evidence. Responses were coded as naïve for the target aspect "empirical absolute versus tentative nature of science" if they included ideas about how science is used to prove facts or the absolute unchanging nature of science. Below is an example of a response coded as naïve for this target aspect.

Science is a continuous process by which different scientific methods are used to prove a hypothesis. The very goal of scientific inquiry is to find an answer to a question and prove it to be correct and valid. (AZ-7)

Responses were coded as informed for this target aspect if they discussed how scientific ideas are subject to change with new evidence. Below is an example of a response coded as informed for this target aspect.

Science is different from other disciplines because it evolves as the knowledge base grown, but also as technology grows. It is rare as a discipline in that it accepts that "Laws" may change as new evidence is presented. $(R B-8)$

\section{Roles Of Anomalous Data}

The target aspect "roles of anomalous data" refers to how anomalous data is identified and handled in science. Responses were coded as naïve for this target aspect if they discussed the roles of anomalies solely as mistakes that could be corrected by simply controlling conditions better. Below is an example of a response coded as naïve for this target aspect.

When an anomaly occurs, scientists should/will repeat the process until they get an accurate result. (AZ-5)

Responses were coded as informed for this target aspect if they discussed how anomalies may lead to new information or cause a model to be re-evaluated. Below is an example of a response coded as informed for this target aspect.

When an anomaly is found, [I think] there are several things that a scientist might do:

a) Try to reproduce the anomaly in order to understand more about how it happened

b) Try to explain the anomaly in terms of the experiment.

c) Consider that perhaps the experiment or the methodology needs to be re-examined or re-designed.

d) Consider that the theory that the experiment is testing may need to be revised (RB-10)

\section{Sociocultural Nature Of Science}

The target aspect "sociocultural nature of science" refers to the subjective nature of science and how it is influenced by the culture and society in which it is conducted. This was not a primary target aspect for the Scientific Inquiry Survey but a enough participants' responses addressed this target resulting in a recurring theme being identified. Participants were categorized as holding naïve views if they referred to science as being totally objective and not influenced by those who conduct it. Below is a response coded as naïve for this target aspect.

Science is more objective than non-science. It does not depend on the personality, nationality, political and religious beliefs of a scientist. (RB-6) 
Participants were categorized as holding informed views if they talked about how science is culturally influenced. Below is a response coded as informed for this target aspect.

[Outcomes of a scientific investigation] depends on personality, on funding, on whether the team has moved on or the equipment isn't available any more. It also depends on the significance of the funding. $(R B-2)$

\section{Use Of Creativity In Science}

The target aspect "use of creativity in science" refers to the role of creativity in all aspects of scientific investigations. As before was not a primary target aspect of the study but several responses emphasized this notion. No participants expressed a naïve view of this target and participants were categorized as holding informed views if they talked about the role of creativity in scientific investigations. Below is an example of a response coded as informed for this target aspect.

Science is also a highly creative process that involves humans observing and interacting with their environment, asking questions, recording accurately, seeking patterns and learning how to use numbers and what value numbers can convey to living systems.(AZ-8)

Not all participants gave responses that discussed all of the targets and some responses included more than one target. From their responses, participants were loosely categorized as holding mostly informed views of the targeted NOS/SI aspects or as holding mostly naïve views of the targeted NOS/SI aspects or as holding a mixture. This was done to compare participants' overall understandings across the targeted NOS/SI aspects.

\section{RESULTS}

Table 1 shows the summary of all participants' pre- and post- program responses categorized as naïve, mixed, or informed for each NOS/SI target. For each target NOS/SI aspect, there is a frequency count of how many total participants were categorized as holding naïve, informed, or mixed views on the pre- and post- survey. Within each category is the total number (in bold) and then the number for each program below. To clarify changes in participants who completed both the pre- and post- surveys, numbers in each category are for those who completed both the pre- and post- surveys, the numbers in parentheses show how many participants were categorized in that category but had only completed either a pre- or post- survey. Changes indicated in the right column illustrate shifts of ideas or addition of ideas for a target aspect for the 38 participants who completed both the pre- and post- survey. The number of participants who used references to their experiences in the research program in their post- responses is also included. 
Table 1: Summary Of All Participants' Responses Categorized For Each Target NOS/SI Aspect

\begin{tabular}{|c|c|c|c|c|c|c|c|c|}
\hline \multirow[t]{2}{*}{$\begin{array}{c}\text { NOS, SI } \\
\text { Aspect }\end{array}$} & \multirow[t]{2}{*}{$\begin{array}{c}\text { Total } \\
\text { Chaco } \\
\text { AZ-START } \\
\text { A-RBSE } \\
\end{array}$} & \multicolumn{3}{|c|}{$\begin{array}{c}\text { Pre } \mathbf{N}=39 \text { (Pre Only = 1) } \\
12 \\
10(1 \text { Pre- Only }) \\
17\end{array}$} & \multicolumn{3}{|c|}{$\begin{array}{c}\text { Post } \mathbf{N}=\mathbf{4 2} \text { (Post Only=4) } \\
14 \text { (2 Post- Only) } \\
11 \text { (2 Post- Only) } \\
17 \\
\end{array}$} & \multirow[t]{2}{*}{$\begin{array}{c}\text { Changes } \\
\text { (Pre-And Post- } \\
(\mathrm{N}=38)\end{array}$} \\
\hline & & Naïve & Mixed & Informed & Naïve & Mixed & Informed & \\
\hline $\begin{array}{l}\text { SM (myth), } \\
\text { questions drive } \\
\text { investigat-ions }\end{array}$ & $\begin{array}{l}\text { Total } \\
\text { Chaco } \\
\text { AZ-START } \\
\text { A-RBSE } \\
\end{array}$ & $\begin{array}{l}7 \\
3 \\
3 \\
1 \\
\end{array}$ & $\begin{array}{c}\mathbf{1 1} \\
4 \\
4 \\
3 \\
\end{array}$ & $\begin{array}{c}15(1) \\
3 \\
2(1) \\
10 \\
\end{array}$ & $\begin{array}{l}\mathbf{4}(\mathbf{1}) \\
2(1) \\
1 \\
1 \\
\end{array}$ & $\begin{array}{c}\mathbf{1 1} \\
5 \\
3 \\
3 \\
\end{array}$ & $\begin{array}{c}18(1) \\
3(1) \\
5 \\
10 \\
\end{array}$ & $\begin{array}{l}1 \text { increased } \\
5 \text { increased } \\
\text { No change }\end{array}$ \\
\hline $\begin{array}{l}\text { Multiple ways } \\
\text { to do science }\end{array}$ & $\begin{array}{l}\text { Total } \\
\text { Chaco } \\
\text { AZ-START } \\
\text { A-RBSE }\end{array}$ & $\begin{array}{c}11(1) \\
5 \\
5(1) \\
1\end{array}$ & $\begin{array}{c}12 \\
3 \\
3 \\
3\end{array}$ & $\begin{array}{c}\mathbf{1 7} \\
4 \\
1 \\
12\end{array}$ & $\begin{array}{l}5(2) \\
3(1) \\
2(1) \\
0\end{array}$ & $\begin{array}{c}\mathbf{1 0} \\
4 \\
4 \\
2\end{array}$ & $\begin{array}{c}22(2) \\
5(1) \\
3(1) \\
14\end{array}$ & $\begin{array}{l}3 \text { increased } \\
4 \text { increased } \\
2 \text { increased }\end{array}$ \\
\hline $\begin{array}{l}\text { Multiple } \\
\text { purposes of } \\
\text { science }\end{array}$ & $\begin{array}{l}\text { Total } \\
\text { Chaco } \\
\text { AZ-START } \\
\text { A-RBSE } \\
\end{array}$ & $\begin{array}{l}2 \\
1 \\
1 \\
0\end{array}$ & $\begin{array}{l}3 \\
1 \\
2 \\
0\end{array}$ & $\begin{array}{c}\mathbf{1 5} \\
6 \\
4 \\
5 \\
\end{array}$ & $\begin{array}{l}\mathbf{1} \\
1 \\
0 \\
0\end{array}$ & $\begin{array}{l}3 \\
1 \\
2 \\
0\end{array}$ & $\begin{array}{c}17(2) \\
7(1) \\
5(1) \\
5\end{array}$ & $\begin{array}{l}1 \text { add post } \\
2 \text { increased } \\
\text { No change }\end{array}$ \\
\hline $\begin{array}{l}\text { Empirical - } \\
\text { based on } \\
\text { evidence }\end{array}$ & $\begin{array}{l}\text { Total } \\
\text { Chaco } \\
\text { AZ-START } \\
\text { A-RBSE }\end{array}$ & $\begin{array}{l}\mathbf{1} \\
1 \\
0 \\
0\end{array}$ & $\begin{array}{l}6 \\
1 \\
4 \\
1\end{array}$ & $\begin{array}{c}15(1) \\
4 \\
3(1) \\
8\end{array}$ & $\begin{array}{l}\mathbf{0} \\
0 \\
0 \\
0\end{array}$ & $\begin{array}{c}7(1) \\
3 \\
3(1) \\
1\end{array}$ & $\begin{array}{c}17(\mathbf{1}) \\
4(1) \\
4 \\
9\end{array}$ & $\begin{array}{l}1 \text { inc } / 1 \text { add post } \\
1 \text { increased } \\
1 \text { add post }\end{array}$ \\
\hline $\begin{array}{l}\text { Empirical - } \\
\text { absolutes } \\
\text { (abstracting and } \\
\text { tentative }\end{array}$ & $\begin{array}{l}\text { Total } \\
\text { Chaco } \\
\text { AZ-START } \\
\text { A-RBSE }\end{array}$ & $\begin{array}{l}\mathbf{5} \\
2 \\
3 \\
0\end{array}$ & $\begin{array}{c}8(1) \\
3 \\
3(1) \\
2\end{array}$ & $\begin{array}{c}\mathbf{1 0} \\
2 \\
1 \\
7\end{array}$ & $\begin{array}{l}3(\mathbf{1}) \\
2(1) \\
1 \\
0\end{array}$ & $\begin{array}{c}11 \\
4 \\
5 \\
2 \\
\end{array}$ & $\begin{array}{c}11(1) \\
2(1) \\
1 \\
8\end{array}$ & $\begin{array}{l}1 \text { add post } \\
2 \text { increased } \\
1 \text { add post }\end{array}$ \\
\hline Anomalies & $\begin{array}{l}\text { Total } \\
\text { Chaco } \\
\text { AZ-START } \\
\text { A-RBSE }\end{array}$ & $\begin{array}{l}9 \\
4 \\
5 \\
0\end{array}$ & $\begin{array}{c}\mathbf{1 0} \\
4 \\
2 \\
4\end{array}$ & $\begin{array}{c}19(1) \\
4 \\
2(1) \\
13\end{array}$ & $\begin{array}{c}\mathbf{5}(\mathbf{2}) \\
3(1) \\
2(1) \\
0\end{array}$ & $\begin{array}{c}\mathbf{1 0} \\
4 \\
3 \\
3\end{array}$ & $\begin{array}{c}23(2) \\
5(1) \\
4(1) \\
14\end{array}$ & $\begin{array}{l}1 \text { increased } \\
3 \text { increased } \\
1 \text { increased }\end{array}$ \\
\hline $\begin{array}{l}\text { Social/ } \\
\text { cultural/ } \\
\text { versus objective }\end{array}$ & $\begin{array}{l}\text { Total } \\
\text { Chaco } \\
\text { AZ-START } \\
\text { A-RBSE }\end{array}$ & $\begin{array}{l}\mathbf{1} \\
1 \\
0 \\
0\end{array}$ & $\begin{array}{l}2 \\
0 \\
1 \\
1\end{array}$ & $\begin{array}{c}\mathbf{1 4} \\
4 \\
4 \\
6\end{array}$ & $\begin{array}{l}\mathbf{0} \\
0 \\
0 \\
0\end{array}$ & $\begin{array}{c}3(\mathbf{1}) \\
1(1) \\
1 \\
1\end{array}$ & $\begin{array}{c}19(1) \\
4(1) \\
6 \\
9\end{array}$ & $\begin{array}{l}1 \text { increased } \\
2 \text { add post } \\
3 \text { add post }\end{array}$ \\
\hline $\begin{array}{l}\text { Use of } \\
\text { Creativity in } \\
\text { Science }\end{array}$ & $\begin{array}{l}\text { Total } \\
\text { Chaco } \\
\text { AZ-START } \\
\text { A-RBSE }\end{array}$ & $\begin{array}{l}\mathbf{0} \\
0 \\
0 \\
0\end{array}$ & $\begin{array}{l}\mathbf{0} \\
0 \\
0 \\
0\end{array}$ & $\begin{array}{l}\mathbf{1} \\
0 \\
0 \\
1\end{array}$ & $\begin{array}{l}\mathbf{0} \\
0 \\
0 \\
0\end{array}$ & $\begin{array}{l}\mathbf{0} \\
0 \\
0 \\
0\end{array}$ & $\begin{array}{c}2(1) \\
1(1) \\
1 \\
1\end{array}$ & $\begin{array}{l}1 \text { add post } \\
\text { No change } \\
\text { No change }\end{array}$ \\
\hline $\begin{array}{l}\text { Program } \\
\text { Reference }\end{array}$ & $\begin{array}{l}\text { Total } \\
\text { Chaco } \\
\text { AZ-START } \\
\text { A-RBSE }\end{array}$ & & N/A & & & $\begin{array}{c}22 \\
9 \\
5 \\
8\end{array}$ & & \\
\hline
\end{tabular}

Of the 39 participants who completed a pre-survey, 17 were classified as holding mostly informed understandings of the nature of science and scientific inquiry ( 3 in Chaco, 2 in AZ-START, and 12 in A-RBSE). Sixteen of those who completed the pre- surveys were classified as holding a mixture of informed and naïve responses ( 5 in Chaco, 6 in AZ-START, and 5 in A-RBSE), one participant did not complete a post- survey. Six overall were classified as holding mostly naïve understandings of the nature of science and scientific inquiry (4 in Chaco and 2 in AZ-START). From pre- to post-survey, 14 participants exhibited notable changes in their pre- to post- responses exhibiting an obvious increase in understanding of at least one NOS/SI category. Only one participant's response resulted in his classification changing from mostly naïve to a mixture of informed and naïve understandings.

On the post-survey, 18 participants were classified as holding mostly informed understandings of the nature of science and scientific inquiry (4 in Chaco, 2 in AZ-START, and 12 in A-RBSE), the additional participant in Chaco only completed a post- survey. Eighteen of those who completed the post- surveys were classified as holding a mixture of informed and naïve responses ( 5 in Chaco, 8 in AZ-START, and 5 in A-RBSE), two participants only completed a post- survey and one was reclassified from mostly naïve understandings on the pre- survey. Six overall were classified as holding mostly naïve understandings of the nature of science and scientific inquiry (5 in Chaco and 1 in AZ-START), one only completed a post- survey. 
Overall, 22 of the 42 (52\%) participants who completed a post- survey used program references in their responses on the post- survey. Of those, 13 participants referred to their own research experiences in the program when discussing anomalies. All 13 discussed how they encountered something unexpected during their project. These most often were characterized by describing errors in data collection, the realization that calculations conducted showed a discrepancy to a previous observation at the same site, and possible mistakes in procedure during the research.

\section{FINDINGS}

Finding 1: Teachers' participation in a science research program resulted in small shifts in their overall understandings of scientific inquiry and nature of science.

Overall, teachers who came in with informed understandings of the target NOS/SI aspects left the program with informed understandings, although in some cases gained understandings specific to a new type of science, either astronomy or biology depending on the program they participated in. The participants who came into the programs with naïve views of most of the target NOS/SI aspects reported gaining a better appreciation of doing science although their research experience resulted in small changes to their understandings of scientific inquiry and nature of science and by the end of the program were also able to talk about more specific science experiences as examples from their research experience The most common naïve views retained were that science was a universal and objective discipline that relies on the algorithmic use of the scientific method and depends on the required use of experiments to further scientific knowledge.

For participants with naïve views of the objective nature of science or algorithmic use of experiments, their research experience did not always change their views about the objective nature of science or the algorithmic use of experiments. Participants who came to their programs with a mixture of informed and naïve understandings of target NOS/SI aspects made small shifts in at least one aspect of scientific inquiry or nature of science but often did not let go of their belief in the objective and universal nature of science or the rigid belief that experiments were the only way to gather scientific data.

Finding 2: Participants' background in science and science research was associated with holding informed views of more target NOS/SI aspects.

Overall, prior experience engaging in scientific research seemed to be the largest contributing factor in a participant's holding more informed views of scientific inquiry and nature of science. The number of years that a participant had taught science did not make a difference in the development of a participant's views of scientific inquiry and nature of science. All participants in the Chaco and AZ-START programs who were classified as holding informed views of most of the target NOS/SI aspects both on their pre- and post- surveys reported at least some prior science research experience. Twelve of the 14 A-RBSE participants who were classified as holding informed views of most of the target NOS/SI aspects reported having previous research experience and all fourteen were selected for the program based on their strong backgrounds in science knowledge. Alternatively there were participants in all three programs who reported having previous science research experience who were classified as holding a mixture of naïve and informed views.

Thus having previous research experience seemed to be an important aspect, although not absolutely essential, to a participant being classified as holding mostly informed views of scientific inquiry and nature of science but could not be used to predict it for all participants. Despite this, having previous research experience did not result in responses being categorized as being mostly informed for the other AZ-START participants. In contrast to the other two programs, teachers in the A-RBSE program had overall much more experience with science research. Not all participants who were categorized as holding mostly informed views of scientific inquiry and nature of science had formal research experience, although all but two did. 


\section{DISCUSSION}

This study is unique in that it investigated subtle changes in participants' understandings of the nature of science and scientific inquiry while looking across multiple programs. Using an instrument tuned specifically for uncovering changes in holistic understandings as well as nuanced changes in growth for specific target NOS/SI aspects made it possible to detect even small growths in understandings of nature of science and scientific inquiry. The detection of these small changes support the previously existing more limited findings of other science research programs for teachers and students in which only small shifts in understandings of science were detected as a result of engaging in science experiences (Bell, Blair, Crawford, \& Lederman, 2003; Buck, 2003; Charney et al, 2007). Notably, these findings contradict those of Varelas, House, and Wenzel (2005) who used in-depth and ongoing interviews possibly allowed their reported observation of nuances of how their teachers' understandings of scientific inquiry evolved which was not possible in this study. More commonly, studies of students and teachers using versions of the VNOS and VOSI instruments to detect changes in participants' understandings of scientific inquiry and nature of science reported similar but less resolved positive increases in understandings as a result of sustained and explicit instruction regarding the nature of science and scientific inquiry (Akerson, Hanson, \& Cullen, 2007; Khishfe \& Abd-El-Khalick, 2002).

Not surprisingly, pre-existing formal science background and science research experiences was a common attribute of teachers who were categorized as holding informed views of more target NOS/SI aspects. This aligns with previous research investigating nature of science knowledge of teachers (Schwartz \& Lederman, 2002). Teachers who were categorized as holding informed views of most of the target aspects of scientific inquiry and nature of science had backgrounds in science. Some held graduate degrees, some had professional science research experience, some conducted research in an undergraduate research program, and some had other professional development training in science. Having a background in science seems to be a consistent pre-requisite for a participant to be categorized as holding mostly informed views of the target NOS/SI aspects but does not guarantee that categorization, and is poised to confound results reported in earlier, less controlled studies. It is also not surprising how many A-RBSE participants were categorized as holding mostly informed views of the target NOS/SI aspects based on their relatively strong science background compared to other participants.

The observation that the amount of teaching experience was not a factor that could be used to distinguish participants' understandings of scientific inquiry provides evidence that these research experiences can be useful to not only beginning science teachers but also teachers who have been in the classroom for many years. This further suggests that sustained or multiple research experiences can lead to more informed understandings of scientific inquiry and nature of science for teachers. Moreover, this provides evidence that knowledge of scientific inquiry and nature of science is not easily attained through teaching alone. Studies of pre-service teachers have shown that experiences that help teachers understand science as a process, including research experiences, result in increases in pre-service teachers' scientific thinking and ability to teach scientific inquiry to their students (Melear, Goodlaxson, Warne, \& Hickok, 2000; Windschitl, 2003).This suggests that research experiences may lead to not only improved understanding of the nature of science and scientific inquiry but may also provide important experiences for inservice teachers who have not experienced research previously.

Participation in a research program resulted in small changes to teachers' understandings of scientific inquiry, nature of science, and science teaching. This conclusion confirms findings from similar work on teacher research programs, which have shown minor changes in participants' understandings of nature of science and scientific inquiry (Dixon \& Wilke, 2007; Govett, 2001). This data in the present study provides higher resolution information than previous quantitative studies, which reported no significant change to teachers' understandings of scientific inquiry (Buck, 2003). This subtle growth observed may not have been detected by existing and more commonly used forced-choice instruments. This emphasizes the utility of using a qualitative research lens instead of a quantitative one. The qualitative nature of the data collected in this study allowed the researcher to better answer the research questions and further investigate interesting results as they were discovered, something for which a forced-choice survey may not have allowed. Participants shifted in small ways in their understandings of scientific inquiry and nature of science as a result of their participation in their respective research programs. Although there were no large shifts detected in participants' overall understandings, teachers did change in several target NOS/SI aspects from their involvement in the research experiences and relied on their direct research experiences when 
making sense of their new understandings. This included shifts in understandings related to how scientific investigations are conducted, from more algorithmic to less algorithmic views of science and the social impacts of science. These findings support previous work that shows that sustained changes in teachers' knowledge of the nature science requires more professional development than short term interventions (Akerson, Cullen, \& Hanson, 2009; Akerson, Morrison, \& McDuffie, 2006). This does not indicate that these experiences are not worthwhile but loudly suggests that stakeholders re-evaluate what outcomes are both reasonable and of most value.

Overall, this study provides further evidence that research experiences for teachers hold some value for helping teachers better understand how science is done in specific contexts and for helping teachers experience small but important changes in their understanding of how science is done. Taken alone, the small changes in teachers' understandings of the nature of science and scientific inquiry might be a disappointing result for stakeholders, many of whom are deeply invested in these programs. However, if these changes are viewed as one part many potential outcomes of these research programs, such as improved teaching practice due to improved understanding of how science is done, then this evidence supports continued efforts at providing teachers with research experiences at some level.

\section{ACKNOWLEDGEMENTS}

This work is based in part on my Ph.D. dissertation at the University of Arizona and portions have been presented previously at the annual meeting of the National Association for Research in Science Teaching, Indianapolis, IN, in March, 2012. I would like to thank Stephanie J. Slater, Erik Brogt, Erin Dokter, and Marti Canipe for their valuable comments, suggested edits, and thoughtful feedback on earlier versions of this paper.

\section{AUTHOR INFORMATION}

Dr. Sanlyn Buxner is an assistant research professor in the College of Education at the University of Arizona and a research scientist and educational specialist at the Planetary Science Institute. Her research includes investigating science literacy of undergraduate students and studying the impact of research and industry experiences on classroom practice. E-mail: buxner@email.arizona.edu

\section{REFERENCES}

Achieve, Inc. on behalf of the twenty-six states and partners that collaborated on the NGSS (2013). Next Generation Science Standards. Achieve, Inc.

Adamson, S. L., Banks, D., Burtch, M., Cox, F., Judson, E., Turley, J. B., et al. (2003). Reformed undergraduate instruction and its subsequent impact on secondary school teaching practice and student achievement. Journal of Research in Science Teaching, 40(10), 939-957.

Akerson, V. L., Cullen, T. A., \& Hanson, D. L. (2009). Fostering a community of practice through a professional development program to improve elementary teachers' views of nature of science and teaching practice. Journal of Research in Science Teaching, 46(10), 1090-1113.

Akerson, V. L., Hanson, D. L., \& Cullen, T. A. (2007). The influence of guided inquiry and explicit instruction on K-6 teachers' views of nature of science. Journal of Science Teacher Education, 18, 751-772.

Akerson, V. L., Morrison, J. A., \& McDuffie, A. R. (2006). One course is not enough: Preservice elementary teachers' retention of improved views of nature of science. Journal of Research in Science Teaching, 43(2), 194-213.

American Association for the Advancement of Science. (1993). Science for all Americans. New York: Oxford University Press.

American Association for the Advancement of Science (AAAS) (2009). Atlas of science literacy. Washington, DC: AAAS and National Science Teachers Association.

Bell, R., Blair, L., Crawford, B.A., \& Lederman, N.G. (2003). Just do it? The impact of a science apprenticeship program on high school students' understandings of the nature of science and scientific inquiry. Journal of Research in Science Teaching, 40, 487-509.

Buck, P. E. (2003). Authentic research experiences for Nevada high school teachers and students. Journal of Geoscience Education, 51(1), 48-53. 
Buxner, S. R. (2010). Exploring the impact of science research experiences for teachers: Stories of growth and identify. Ph.D. Dissertation, University of Arizona. http://hdl.handle.net/10150/195355

Charney, J., Hmelo-Silver, C. E., Sofer, W., Neigeborn, L., Coletta, S., \& Nemeroff, M. (2007). Cognitive apprenticeship in science through immersion in laboratory practices. International Journal of Science Education, 2(5), 195-213.

Deng, F., Chen, D. T., Tsai, C. C., \& Chai, C. S. (2011). Students' views of the nature of science: A critical review of research. Science Education, 95(6), 961-999.

Dixon, P., \& Wilke, R. A. (2007). The influence of a teacher research experience on elementary teachers' thinking and instruction. Journal of Elementary Science Education, 19(1), 25 - 43.

Dresner, M., \& Worley, E. (2006). Teacher research experiences, partnerships with scientists, and teacher networks sustaining factors from professional development. Journal of Science Teacher Education, 17, 1-14.

Driver, R., Leach, J., Millar, R., \& Scott, P. (1996). Young people's images of science. Buckingham, UK: Open University Press.

Elby, A., \& Hammer, D. M. (2001). On the substance of a sophisticated epistemology. Science , 85, 554-567.

Gess-Newsome, J. (2002). The use and impact of explicit instruction about the nature of science and science inquiry in an elementary science methods course. Science and Education, 11, 55-67.

Govett, A. L. (2001). Teachers' conceptions of the nature of science: Analyzing the impact of a teacher enhancement program in changing attitudes and perceptions of science and scientific research. (Doctoral dissertation). Available from Dissertations and Theses database. (UMI No. 3012825).

Khishfe, R., \& Abd-El-Khalick, F. (2002). Influence of explicit and reflective versus implicit inquiry-oriented instruction on sixth graders' views of nature of science. Journal of Research in Science Teaching, 39(7), 551-578.

Lave, J., \& Wenger, E. (1991). Situated learning: legitimate peripheral participation. New York: Cambridge University Press.

Lederman, N. G., Abd-El-Khalick, F. Bell, R. L, \& Schwartz, R. S. (2002). Views of Nature of Science Questionnaire; Toward valid and meaningful assessment of learners' conceptions of nature of science. Journal of Research in Science Teaching, 39(6), 497-521.

Lederman, N. G. (2007). Nature of science: Past, present, and future. In S. K. Abell \& N. G. Lederman (Eds.), Handbook of Research on Science Education (pp. 831-879). Mahwah, NJ: Lawrence Erlbaum.

Luera, G. R., \& Otto, C. A. (2005). Development and evaluation of an inquiry-based elementary science teacher education program reflecting current reform movements. Journal of Science Teacher Education, 16, 241258.

Melear, C. T., Goodlaxson, J. D., Warne, T. R., \& Hickok, L. G. (2000). Teaching preservice science teachers how to do science: Responses to research experience. Journal of Science Teacher Education, 11(1), 77-90.

Miles, M. B., \& Huberman, A. M. (1994). Qualitative data analysis: An expanded sourcebook, 2nd ed. Thousand Oaks, CA: Sage

National Research Council. (1996). National Science Education Standards. Washington, DC: National Academy Press.

National Research Council. (2000). Inquiry and the National Science Education Standards: A guide for teaching and learning. Washington, D.C.: National Academy Press.

National Research Council. (2011). A Framework for K-12 Science Education: Practices, Crosscutting Concepts, and Core Ideas. Washington, DC: National Academy Press.

NGSS Lead States (2013). Next generation science standards: For states, by states. Washington, DC: National Academies Press.

National Science Foundation (2014). http://www.retnetwork.org

O'Neal, M. L. (2003). Field-based research experience in earth science teacher education. Journal of Geoscience Education, 51(1), 64-70.

Schwartz, R. S., \& Lederman, N. G. (2002). "It's the nature of the beast": The influence of knowledge and intentions on learning and teaching nature of science. Journal of Research in Science Teaching, 39(3), 205-236.

Schwartz, R. S., \& Lederman, N. G. (2004, April). Epistemological views in authentic science practice: A crossdiscipline comparison of scientists' views of nature of science and scientific inquiry. Paper presented at the annual international meeting of the National Association for Research in Science Teaching, Vancouver, B.C., Canada. 
Schwartz, R. S. (2004). Epistemological views in authentic science practice: A cross-discipline comparison of scientists' views of nature of science and scientific inquiry. Ph.D. Dissertation Oregon State University, Corvallis.

Schwartz, R., \& Lederman, N. (2006, April). Scientists' epistemological views of science. Paper presented at the annual conference of the American Educational Research Association. San Francisco, CA.

Schwartz, R. S., \& Lederman, N. (2008). What scientists say: Scientists' views of nature of science and relation to science context. International Journal of Science Education. 30(6), 727-771.

Schwartz, R. S., Lederman, N. G., \& Crawford, B. (2004). Developing views about nature of science in authentic contexts: An explicit approach to bridging the gap between nature of science and scientific inquiry. Science Education, 88(4), 610-645.

Schwartz, R. S., Lederman, N., \& Lederman, J. (2008, April). An instrument to assess Views of Scientific Inquiry: The VOSI questionnaire. Paper presented at the annual meeting of the National Association for Research in Science Teaching, Baltimore, MD.

Schwartz, R. S., Lederman, N. G., \& Thompson, R. (2001, March). Grade nine students' views of nature of science and scientific inquiry: The effects of an inquiry-enthusiast's approach to teaching science as inquiry. Paper presented at the annual meeting of the National Association for Research and Science Training, St. Louis, MO.

Silverstein, S. C., Dubner, J., Miller, J., Glied, S., \& Loike, J. D. (2009). Teachers' participation in research programs improves their students' achievement in science. Science, 326, 440-442.

Tobias, S., \& Baffert, A. (2009). Science teaching as a profession: Why it isn't and how it could be. Tucson, AZ: Research Corporation for Science Advancement.

Varelas, M., House, R., \& Wenzel, S. (2005). Beginning teachers immersed into science: Scientist and science teacher identities. Science Education, 89(3), 492-516.

Windschitl, M. (2003). Inquiry projects in science teacher education: What can investigative experiences reveal about teacher thinking and eventual classroom practice? Science Education, 87, 112-143. 


\section{APPENDIX: Science Inquiry Survey}

\section{Science Inquiry Pre-Program Survey}

1a) What, in your view, is science? What makes science (or a scientific discipline such as physics, biology, etc.) different from other disciplines (e.g., religion, philosophy, history)?

1b) Does the development of scientific knowledge require experiments? Explain and give an example to justify your position.

2a) How do you define "scientific inquiry"?

2b) Give an example that represents your view of scientific inquiry.

2c) Do you think there is more than one approach to science inquiry? Please explain, giving examples if possible.

3a) What do you think the purpose(s) of scientific inquiry is?

3b) Do you think all scientific inquiry has the same purpose? Why or why not?

4) Scientists sometimes encounter inconsistent findings (anomalous information). Consider your own experiences in research:

4a) How are anomalies identified? (i.e., What is an example of an "inconsistent" finding in your field of research/experience?) Provide an example.

4b) What does a scientist do when an anomaly is identified?

4c) Do you think all scientists identify and handle anomalous information this same way? Why or why not?

\section{Science Inquiry Post-Program Survey}

6a) What in your view, is science? What makes science (or a scientific discipline such as physics, biology, etc.) different from other disciplines (e.g., religion, philosophy, history)?

6b) Does the development of scientific knowledge require experiments. Explain and give an example to justify your position.

7) How do you define "scientific inquiry"? Please give an example that represents your view.

8b) Do you think there is more than one approach to science inquiry? Please explain, giving examples if possible.

9a) What do you think the purpose(s) of scientific inquiry is?

9b) Do you think all scientific inquiry has the same purpose? Why or why not?

10) Scientists sometimes encounter inconsistent findings (anomalous information).

Consider your own experiences:

10a) How are anomalies identified? (i.e., What is an example of an "inconsistent" finding in your field of research/experience?) Provide an example.

10b) What does a scientist do when an anomaly is identified?

10c) Do you think all scientists identify and handle anomalous information this same way? Why or why not?

11) Based off of your experience this week, what type of information is critical for scientists to justify and accept a scientific claim? Use an example if possible. 


\section{NOTES}

